\title{
Association between severity of COVID-19 and clinical and biochemical characteristics: a cross- sectional study
}

\section{Dan Wang}

Department of Neurology, Zhongshan Hospital of Hubei Province, Wuhan, China

\section{Rui-Fang Li}

Department of Neurology, Zhongshan Hospital of Hubei Province, Wuhan, China

\section{Juan Wang}

Department of Radiology, Tongji Hospital, Huazhong University of Science and Technology, Wuhan, China

\section{Qun-Qun Jiang}

Department of Infectious Diseases, Zhongnan Hospital of Wuhan University, Wuhan, China

\section{Chang Gao}

Department of Neurology, Zhongshan Hospital of Hubei Province, Wuhan, China

\section{Juan Yang}

Department of Neurology, Zhongshan Hospital of Hubei Province, Wuhan, China

\section{Lin-Tong Ge}

Department of Neurology, Zhongshan Hospital of Hubei Province, Wuhan, China

Qing Hu (D hqzsyy@126.com)

Department of Neurology, Zhongshan Hospital of Hubei Province, Wuhan, China https://orcid.org/0000-0002-1041-1642

\section{Research Article}

Keywords: SARS-CoV-2, COVID-19, correlation analysis, prognostic indicator

Posted Date: March 24th, 2020

DOI: https://doi.org/10.21203/rs.3.rs-18482/v1

License: (1) (1) This work is licensed under a Creative Commons Attribution 4.0 International License. Read Full License 


\section{Abstract}

Background: Coronavirus Disease 2019 (COVID-19) is a novel infectious disease caused by the severe acute respiratory syndrome coronavirus 2 (SARS-CoV-2) emerged in Wuhan and has quickly spread across the world. The mortality rate in critically ill patients with COVID-19 is high. This study analyzed clinical and biochemical parameters between mild and severe patients, helping to identify severe or critical patients early.

Methods: In this single center, cross-sectional study, 143 patients were included and divided to mild/moderate and sever/critical groups. Correlation between the disease criticality and clinical features and peripheral blood biochemical markers was analyzed. Cut-off values for critically ill patients were speculated through the ROC curve.

Results $\triangle$ Significantly, disease severity was associated with age $(r=0.458, P<0.001)$, comorbidities $(r=$ $0.445, P<0.001)$, white cell counts $(r=0.229, P=0.006)$, neutrophil count $(r=0.238, P=0.004)$, lymphocyte count $(r=-0.295, P<0.001)$, albumin $(r=-0.603, P<0.001)$, high-density lipoprotein cholesterol $(r=-0.362, P<0.001)$, serum potassium $(r=-0.237, P=0.004)$, plasma glucose $(r=0.383, P<$ $0.001)$, total bilirubin $(r=0.340, P<0.001)$, serum amyloid $A(r=0.58, P<0.001)$, procalcitonin $(r=$ $0.345, P<0.001)$, C-reactive protein $(r=0.477, P<0.001)$, lactate dehydrogenase $(r=0.548, P<0.001)$, aspartate aminotransferase $(r=0.342, P<0.001)$, alanine aminotransferase $(r=0.264, P=0.001)$, erythrocyte sedimentation rate $(r=0.284, P=0.001)$ and $D$-dimer $(r=0.477, P \otimes 0.001)$.

Conclusion: With following parameters such as age $>52$ years, C-reactive protein $>64.79 \mathrm{mg} / \mathrm{L}$, lactate dehydrogenase $>245 \mathrm{U} / \mathrm{L}$, D-dimer $>0.96 \mathrm{ug} / \mathrm{mL}$, serum amyloid $A>100.02 \mathrm{mg} / \mathrm{L}$, or albumin $\otimes 36 \mathrm{~g} / \mathrm{L}$, the progress of COVID-19 to critical stage should be closely observed and possibly prevented. Lymphocyte count, serum potassium and procalcitonin may also be a prognostic indicator.

\section{Background}

A novel coronavirus, designated as the severe acute respiratory syndrome coronavirus 2 (SARS-CoV-2), was first identified in Wuhan, China in December 2019 ". SARS-CoV-2 is highly infectious and asymptomatic patients may also become the source of infection ${ }^{\square}$. World Health Organization (WHO) announced that the disease caused by SARS-CoV-2 was Corona Virus Disease 2019 (COVID-19) on 11 February, 2020. Patients with COVID-19 have a series of clinical manifestations, such as pharyngalgia, fever, cough, fatigue, anorexia, headache, diarrhea, nausea or vomiting, dyspnea $\square$, even acute respiratory distress syndrome (ARDS). A lot of severe or critical patients had to been admitted to the intensive care unit (ICU). According to the reported clinical characteristics of patients with COVID-19, the total mortality ranges from $2-5 \%$, which can be even higher in the elders $\square$. Wuhan city, as the epidemic area, the mortality reached a peak of over $7 \%$ at the early stage $\square$. 
Although most patients with COVID-19 were mild in the early days, some patients progressed rapidly to acute respiratory failure, metabolic acidosis, septic shock, ARDS or death. Early identification of risk factors for critical patients could facilitate appropriate supportive care and thus reduce the mortality $\square$. A study of the first 138 laboratory-confirmed cases with COVID-19 showed the changes of neutrophil count, lymphocyte counts, and D-dimer levels $\square$. Increased inflammation -related indicators were found in patients with COVID-19, including erythrocyte sedimentation rate (ESR), interleukin-6 and C-reactive protein (CRP) ${ }^{[4]}$. However, little is known about the relationship between disease severity and clinical and biochemical features in Patients with COVID-19.

In this study, we performed a comprehensive evaluation of characteristics of 143 patients with COVID-19 admitted to Zhongshan Hospital, Wuhan. This study retrospectively analyzed clinical characteristics and biochemical parameters between mild/moderate and severe/critical patients, which may help to identify critical cases and perform appropriate clinical intervention early.

\section{Methods}

\section{Study Design and Participants}

This study was a cross-sectional study, and all consecutive patients with confirmed COVID-19 admitted to Zhongshan Hospital from January 15, 2020 to February 28, 2020, were enrolled. Zhongshan Hospital, located in Wuhan, Hubei Province, the endemic areas of SARS-CoV-2, is one of the major public hospitals and is responsible for the treatments for COVID-19 assigned by the government. Diagnosis of COVID-19 and clinical classification according to the new coronavirus pneumonia diagnosis and treatment plan (trial version 7) developed by the National Health Committee of the People's Republic of China ${ }^{\left[{ }^{[}\right]}$.

The clinical classifications are as follows: (1) mild, minor symptoms and imaging shows no pneumonia. (2) moderate, with fever, respiratory tract symptoms, and imaging shows pneumonia. (3) severe, meet any of the following: a) respiratory distress, respiratory rate $\geq 30$ beats $/ \mathrm{min} ; \mathrm{b}$ ) in the resting state, means oxygen saturation $\leq 93 \%$; c) arterial blood oxygen partial pressure/oxygen concentration $\leq 300 \mathrm{mmHg}$ $(1 \mathrm{mmHg}=0.133 \mathrm{kPa}) ; \mathrm{d})$ pulmonary imaging showed that the lesion progressed more than $50 \%$ within 24-48 hours. (4) critical, one of the following conditions: a) respiratory failure occurs and requires mechanical ventilation; b) Shock occurs; c) ICU admission is required for combined organ failure.

In this study, patients with mild or moderate symptoms were classified as mild/moderate group, and patients with severe or critical symptoms were classified as severe/critical group.

\section{Data Collection}

All suspected infection patients were taken upper respiratory throat swab samples at admission and then shipped to designated authoritative laboratories to detect the SARS-CoV-2. Bacterial and fungal detections of sputum or respiratory secretions and other laboratory tests were completed in the clinical laboratory in Zhongshan Hospital. C-reactive protein (CRP) was detected by immunoturbidimetry method. 
Procalcitonin (PCT) was detected by Roche electrochemiluminescence method. Erythrocyte sedimentation rate (ESR) was measured by Westergren's international standard method.

We retrospectively analyzed and evaluated the epidemiological history, comorbidity, vital signs, and symptoms obtained from electronic medical records. The data collection forms were reviewed independently by two experienced physicians.

\section{Statistical analysis}

Categorical variables were given as frequency rates and percentages; continuous variables were defined using mean, median, and interquartile range (IQR) values. The Kolmogorov-Smirnov test was used to verify the normality of distribution of continuous variables. The independent sample t test or the MannWhitney $\mathrm{U}$ test was used for the continuous variables and the chi-square test for categorical variables. In correlation analysis, Pearson correlation coefficient was used for the variables of normal distribution, Spearman correlation coefficient for those of skewed distribution. Receiver-operating characteristic (ROC) curve analysis was used to determine the optimum cut-off points of parameters for severe patients. Statistical analyses were performed using SPSS 24.0 (SPSS Inc, Chicago, IL, USA) and MedCalc19.0.4. A 2-tailed $P<0.05$ was considered as statistically significant.

\section{Result}

The study population included 143 hospitalized patients with confirmed COVID-19. The median age was 58 years (IQR, 39-67; range, 14-84 years), and $73(51.0 \%)$ were men. Of the 143 patients, $50(35.0 \%)$ had 1 or more comorbidities. Hypertension (36 [25.2\%]), cardiovascular disease (16 [11.2\%]) and diabetes (13 [9.1\%]) were the most common coexisting conditions. The most common symptoms at initial stage of illness were fever (137 [95.8\%]), fatigue (93 [65.0\%]), dry cough (78 [54.5\%]), anorexia (66 [46.2\%]), chest tightness (63 [44.1\%]), myalgia (49 [34.3\%]), mild shortness of breath (48 [33.6\%]), chill (33 [23.1\%]) and dyspnea (31 [21.7\%]). Less common symptoms were nausea or vomiting, diarrhea and headache (Table 1).

Compared with mild/moderate group $(n=72)$, severe/critical group $(n=71)$ were significantly older (median age, 65 years [IQR, 53-69] vs 44 years [IQR, 32-60]; $\mathrm{P}<0.001)$ and were more likely to have underlying comorbidities, including hypertension (31 [43.7\%] vs 5 [6.9\%], and cardiovascular disease (12 [16.9\%] vs 4 [5.6\%]). Compared with the mild/moderate group, severe/critical group were more likely to report anorexia, expectoration, mild shortness of breath, dyspnea and myalgia.

There were numerous differences in laboratory findings between mild/moderate group and severe/critical group, including white blood cell, neutrophil counts, and lymphocyte count, as well as levels of highdensity lipoprotein cholesterol $\triangle \mathrm{HDL}-\mathrm{C} \bigotimes$, plasma glucose, serum potassium, total bilirubin (TBIL), albumin, aspartate aminotransferase (AST), alanine aminotransferase (ALT), lactate dehydrogenase (LDH), D- 
dimer, erythrocyte sedimentation rate (ESR), serum amyloid A (SAA), C-reactive protein (CRP) and procalcitonin (PCT) (Table 2).

Significant correlations were found about age, comorbidities, white blood cell count, neutrophil count, lymphocyte count, plasma glucose, serum potassium, albumin, D-dimer, HDL-C, TBIL, AST, ALT, LDH, ESR, SAA, CRP and PCT. Strikingly, this analysis revealed negative correlation between disease severity and lymphocyte count, albumin, serum potassium, and HDL-C (Table3). Age $(r=0.458)$, comorbidities $(r=$ $0.445)$, LDH $(r=0.548)$, D-dimer $(r=0.477)$, SAA $(r=0.58)$, CRP $(r=0.477)$ were moderately correlated and albumin $(r=-0.603)$ was highly correlated ${ }^{[i]}$.

To better detect the severe illness, the ROC curve of age was administrated and listed in Figure 1A (AUC = $0.746,95 \% \mathrm{Cl}: 0.686-0.831, \mathrm{P} \otimes 0.001)$. The best cut-off point of age was 52 years with a sensitivity of $76.1 \%$ and specificity of $63.9 \%$. ROC curve of LDH (AUC $=0.816,95 \% \mathrm{Cl}: 0.743-0.876, \mathrm{P} \otimes 0.001$, Figure 1B) suggested the best cut-off point was $245 \mathrm{U} / \mathrm{L}$ with a specificity of $69.4 \%$ and a sensitivity of $85.9 \%$. ROC curve of D-dimer (AUC $=0.775,95 \% \mathrm{Cl}: 0.698-0.841, \mathrm{P} \otimes 0.001$, Figure 1C) suggested the best cut-off point was $0.96 \mathrm{ug} / \mathrm{mL}$ with $77.0 \%$ specificity and $78.1 \%$ sensitivity. ROC curve of SAA (AUC $=0.835,95 \%$ Cl: $0.764-0.892, P \otimes 0.001$, Figure 1D) indicated the best cut-off point was $100.02 \mathrm{mg} / \mathrm{L}$ with $72.2 \%$ specificity and $85.9 \%$ sensitivity. ROC curve of albumin (AUC $=0.848,95 \% \mathrm{Cl}: 0.779-0.903, \mathrm{P} \otimes 0.001$, Figure 1E) indicated the best cut-off point was $36 \mathrm{~g} / \mathrm{L}$ with a specificity of $83.3 \%$ and a sensitivity of $85.9 \%$. ROC curve of CRP (AUC $=0.776,95 \%$ Cl: $0.698-0.841, P \otimes 0.001$, Figure $1 F$ ) suggested the best cut-off point was $64.79 \mathrm{mg} / \mathrm{L}$ with a specificity of $81.9 \%$ and a sensitivity of $64.8 \%$.

As shown in Figure 2, the area under the ROC curve for albumin is the biggest, but it's not statistically significant. Binary logistic regression was applied to calculate the predictive probability of combined indicators for the speculation of disease severity. The combined indicators found that the AUC reached 0.921 (95\% Cl: $0.864-0.959, P \otimes 0.001$, Figure $3 \mathrm{~A}$ ), with a sensitivity of $87.3 \%$ and a specificity of $80.6 \%$. The area difference between the combined indicators and albumin was 0.0726 (95\% Cl: $0.0125-0.133, P$ $=0.0179$, Figure $3 \mathrm{~B}$ ), indicating that the accuracy of the combined identification of the six indicators was the best.

\section{Discussion}

The SARS-CoV-2 outbreaking at the end of 2019 is highly contagious and more than 80,000 patients have been reported in Chinese mainland [[i]]. The number of confirmed cases worldwide has risen by 7,499 to 132,758 , among which nearly 28,900 were reported in the European region [[ii]]. Most patients are mild to moderate severity, and with a better prognosis [[iii]]. However, for patients developing into severe or critical levels, the mortality rate was markedly increased. It is important to identify critically ill patients even earlier, aiming to reduce mortality and improve the recovery rate.

In this study, the relationship between disease severity and clinical and biochemical indicators was comprehensively analyzed. Most critical ill patients were older and had a greater number of comorbid 
conditions than patients with mild to moderate illness. This was consistent with a study ${ }^{[7]}$ in which prospectively included 138 patients with COVID-19 and the researcher suggested that age and comorbidity may be risk factors for poor outcome. Moreover, our study showed that the ROC curve of age was administrated, and the best cut-off point of age was 52 years.

In accordance with Liu J's ${ }^{[[\mathrm{iv}]}$ and Wan S's ${ }^{[\mathrm{W}]}$ study, this study also found that the levels of lymphocyte count, neutrophil counts and CRP were associated with the severity of COVID-19. In addition, ESR, PCT, Ddimer and SAA were also related to the disease severity. PCT levels in serum increase when severe bacterial, fungal and systemic inflammatory response syndrome occur, and it is generally not elevated with virus infections ${ }^{[\mathrm{v}]}$. In our study, PCT concentration in severe/critical patients was significantly higher than that in the mild/moderate group when PCT $\geq 0.04 \mathrm{ng} / \mathrm{mL}$. It suggested the possibility of multiple infections in critically ill patients. Besides, we also found that the levels of HDL-C and serum potassium were negatively correlated with the severity of COVID-19. According to Dong C's ${ }^{\left[{ }^{[v i]}\right]}$ study, hypokalemia was prevailing in patients with COVID-19, and the correction of hypokalemia was challenging because of continuous renal $\mathrm{K}+$ loss resulting from the degradation of ACE2. Therefore, Serum potassium may be a good prognostic index.

In this study, there were also some other abnormal indicators that had significant differences between the mild/moderate and severe/critical groups, such as plasma glucose, TBIL, AST, ALT, and LDH. These abnormalities suggested that SARS-CoV-2 infection may be associated with myocardia injury, hepatic injury and other related organ damage. Based on ROC analysis between mild/moderate and severe/critical patients, some cut-off values of the test items were obtained. With age $>52$ years, CRP > $64.79 \mathrm{mg} / \mathrm{L}, \mathrm{LDH}>245 \mathrm{U} / \mathrm{L}, \mathrm{D}$-dimer $>0.96 \mathrm{ug} / \mathrm{mL}, \mathrm{SAA}>100.02 \mathrm{mg} / \mathrm{L}$, albumin $\otimes 36 \mathrm{~g} / \mathrm{L}$, progress to critical illness should be closely observed and prevented.

This study has several limitations. First, it is a pity that some inflammatory factors and immunological indexes cannot be detected and compared due to the limitation of experimental conditions. Second, this is a cross-sectional study and participants were from 1 center rather than multiple centers. It provides no information regarding cause or effect relationship. Although we found significant associations, further studies are needed to investigate clinical significance of these indicators on patients with COVID-19.

\section{Conclusions}

With following parameters such as age $>52$ years, C-reactive protein $>64.79 \mathrm{mg} / \mathrm{L}$, lactate dehydrogenase $>245 \mathrm{U} / \mathrm{L}$, D-dimer $>0.96 \mathrm{ug} / \mathrm{mL}$, serum amyloid $A>100.02 \mathrm{mg} / \mathrm{L}$, or albumin $\otimes 36 \mathrm{~g} / \mathrm{L}$, the progress of COVID-19 to critical stage should be closely observed and possibly prevented. Lymphocyte count, serum potassium and procalcitonin may also be a prognostic indicator.

\section{Abbreviations}

COVID-19: Coronavirus Disease 2019 
SARS-CoV-2: Severe acute respiratory syndrome coronavirus 2

WHO: World Health Organization

ARDS: Acute respiratory distress syndrome

ICU: Intensive care unit

ESR: Erythrocyte sedimentation rate

CRP: C-reactive protein

PCT: Procalcitonin

IQR: Interquartile range

ROC: Receiver-operating characteristic

HDL-C: High-density lipoprotein cholesterol

LDL-C: Low-density lipoprotein cholesterol

TBIL: Total bilirubin

AST: Aspartate aminotransferase

ALT: Alanine aminotransferase

LDH: Lactate dehydrogenase

SAA: Serum amyloid A

BUN: Blood urea nitrogen

CK-MB: Creatine kinase-muscle and brain type

APTT: Activated partial thromboplastin time

PT: Prothrombin time

AUC: Area under the ROC curve

\section{Declarations}

Acknowledgements 
We thank Liang-Long Peng, the best friend of my life, for his reviewing and editing the diagrams and images.

\section{Authors' contributions}

Dan Wang designed research and conceived the experiments. Dan Wang, Rui-Fang Li, Qun-Qun Jiang, Juan Wang, Chang Gao, Juan Yang, Qing Hu and Lin-Tong Ge conducted the experiments and analyzed the results. Dan Wang wrote the manuscript. All authors read and approved the final manuscript.

\section{Funding}

Not applicable.

\section{Availability of data and materials}

The datasets used and/or analysed during the current study are available from the corresponding author on reasonable request.

\section{Ethics approval and consent to participate}

This study was approved by the ethical committee of Zhongshan Hospital. Because of the infectivity and the exploration urgency for COVID-19, written informed consent was waived. Oral consent was obtained from patients.

\section{Consent for publication}

Not applicable.

\section{Competing interests}

The authors declare that they have no competing interests.

\section{References}

1. Huang C, Wang Y, Li X, Ren L, Zhao J, Hu Y, et al. Clinical features of patients infected with 2019 novel coronavirus in Wuhan, China. Lancet. 2020. https://doi. org/10.1016/S0140-6736(20)30183-5.

2. General Office of the National Health Commission. Notice on the novel coronavirus infection diagnosis and treatment plan (trial version sixth). General Office of the National Health Commission. cited March 10, 2020. Available: http://www.nhc.gov.cn/yzygj/s7653p/202002/8334a8326dd94d329df351d7da8aefc2.shtml.

3. National Health Commission Stroke Prevention and Control Engineering Expert Committee. Expert consensus on prevention and control of novel coronavirus infection in neurology (version first). National Health Commission Stroke Prevention and Control Engineering Expert Committee. cited March 10, 2020. Available: http://www.cnstroke.Com/NewsInfo/News/News DetailWeb? Tid=2621. 
4. Chen N, Zhou M, Dong X, et al. Epidemiological and clinical characteristics of 99 cases of 2019 novel coronavirus pneumonia in Wuhan, China: a descriptive study. Lancet 2020; published online Jan 30; doi: 10.1016/S0140-6736(20)30211-7.

5. Lu JT, Hu SF, Fan R, et al. ACP risk grade: a simple mortality index for patients with confirmed or suspected severe acute respiratory syndrome coronavirus 2 disease (COVID-19) during the early stage of outbreak in Wuhan, China. medRxiv 2020. 02. 20. 20025510; doi: https://doi.org/10.1101/2020.02.20.20025510.

6. Liu JY, Liu Y, Xiang P, et al. Neutrophil-to-Lymphocyte Ratio Predicts Severe Illness Patients with 2019 Novel Coronavirus in the Early Stage. medRxiv 2020. 02. 10. 20021584; doi: https://doi.org/10. 1101/2020. 02. 10. 20021584.

7. Wang DW, Hu B, Hu C, et al. Clinical characteristics of 138 hospitalized patients with 2019 novel coronavirus-infected pneumonia in Wuhan, China[J]. JAMA, 2020; doi: 10. 1001/ jama. 2020.1585.

8. General Office of the National Health Commission. Notice on the novel coronavirus infection diagnosis and treatment plan (trial version seventh). General Office of the National Health Commission. cited March 11, 2020. Available: http://www.nhc.gov.cn/yzygj/s7653p/202003/46c9294a7dfe4cef80dc7f5912eb1989.shtml.

9. Salkind, N. J. Ice cream and crime - Calculation of correlation coefficient. In: Neil J. Salkind, editors. Statistics for People Who (Think They) Hate Statistics. London: Academic;2008. P 58-65.

10. China Daily Network. Big data on COVID-19 around the world, updated at 24:00 March 15, 2020. China Daily Network. cited March 16, 2020. Available: https: //www.chinadaily.com.cn/china/special_coverage/2020latestdata.

11. China Daily Network. COVID-19 confirmed cases top 50,000 outside China. China Daily Network. cited March 14, 2020. Available: https://www. chinadaily. com. cn /a/202003/14/ WS5e6c2687a31012821727f108. html.

12. The Novel Coronavirus Pneumonia Emergency Response Epidemiology Team, The epidemiological characteristics of an outbreak of 2019 novel coronavirus diseases (covid-19) in china [J]. Zhonghua Liu Xing Bing Xue Za Zhi, 2020,41(2):145-151.

13. Liu J, Li S, et al. Longitudinal characteristics of lymphocyte responses and cytokine profiles in the peripheral blood of SARS-CoV-2 infected patients, medRxiv preprint 2020, doi: https://doi.org/10.1101/2020.02.16.20023671.

14. Wan S, Yi Q, Fan S, et al. Characteristics of lymphocyte subsets and cytokines in peripheral blood of 123 hospitalized 2 patients with 2019 novel coronavirus pneumonia (NCP), medRxiv preprint 2020, doi: https://doi. Org/10. 1101/2020. 02. 16.20023671.

15. Albrich WC, Harbarth S. Pros and cons of using biomarkers versus clinical decisions in start and stop decisions for antibiotics in the critical care setting [J]. Intensive Care Med, 2015,41(10):1739-1751.

16. Chen D, Li XK, Song QF, Hu CC, Su FF, Dai JY. Hypokalemia and Clinical Implications in Patients with Coronavirus Disease 2019 (COVID-19). medRxiv 2020. 02. 27. 20028530; doi: https://doi.org/10.1101/2020.02.27.20028530. 


\section{Tables}

Table 1. Demographics and baseline characteristics of patients with COVID-19 


\begin{tabular}{|c|c|c|c|c|}
\hline & \multicolumn{3}{|l|}{ No. (\%) } & \multirow{2}{*}{$\begin{array}{l}\mathbf{P} \\
\text { Value } \\
\mathrm{a}\end{array}$} \\
\hline & Total(N=143) & $\begin{array}{l}\text { Mild/Moderate } \\
(\mathrm{n}=72)\end{array}$ & Severe/Critical $\| \mathrm{n}=71 \square$ & \\
\hline $\begin{array}{l}\text { Age, median (IQR), y } \\
\text { Sex }\end{array}$ & $58(39-67)$ & $44(32-60)$ & $65(53-69)$ & $\begin{array}{l}0.000 \\
0.009\end{array}$ \\
\hline $\begin{array}{l}\text { Female } \\
\text { Male }\end{array}$ & $\begin{array}{l}70(49.0) \\
73(510)\end{array}$ & $\begin{array}{l}43(59.7) \\
29(40.3)\end{array}$ & $\begin{array}{l}27(38.0) \\
44(62.0)\end{array}$ & \\
\hline $\begin{array}{l}\text { Huanan Seafood } \\
\text { Wholesale Market }\end{array}$ & $11(7.7)$ & $4(5.6)$ & $7(9.7)$ & 0.359 \\
\hline $\begin{array}{l}\text { Comorbidities } \\
\text { Hypertension }\end{array}$ & $\begin{array}{l}50(35.0) \\
36(25.2)\end{array}$ & $\begin{array}{l}10(13.9) \\
5(6.9)\end{array}$ & $\begin{array}{l}40(56.3) \\
31(43.7)\end{array}$ & $\begin{array}{l}0.000 \\
0.000\end{array}$ \\
\hline Cardiovascular disease & $16(11.2)$ & $4(5.6)$ & $12(16.9)$ & 0.031 \\
\hline Diabetes & $13(9.1)$ & $4(5.6)$ & $9(12.7)$ & 0.139 \\
\hline Chronic obstructive & $10(7.0)$ & $3(4.2)$ & $7(9.9)$ & 0.091 \\
\hline Cerebrovascular disease & $5(3.5)$ & $2(2.8)$ & $3(4.2)$ & 0.987 \\
\hline Signs and symptoms & 137(95.8) & $70(97.2)$ & $67(94.4)$ & 0.619 \\
\hline Ention & $93(65.0)$ & $42(58.3)$ & $51(71.8)$ & 0.091 \\
\hline Dminomat & $78(54.5)$ & $37(51.4)$ & $41(57.7)$ & 0.455 \\
\hline 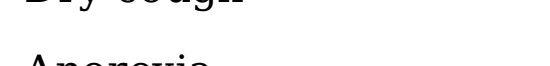 & $66(46.2)$ & $23(31.9)$ & $43(60.6)$ & 0.001 \\
\hline Allorexid & $63(44.1)$ & $29(40.3)$ & $34(47.9)$ & 0.359 \\
\hline Chest hightiless & $49(34.3)$ & $18(25.0)$ & $31(43.7)$ & 0.019 \\
\hline Mild olbontnoge of bmosth & $48(33.6)$ & $33(45.8)$ & 15(21.1) & 0.002 \\
\hline & $33(23.1)$ & $19(26.4)$ & $14(19.7)$ & 0.344 \\
\hline & $31(21.7)$ & $10(13.9)$ & $21(29.6)$ & 0.023 \\
\hline Dhonmonglotio & 28(19.6) & $12(16.7)$ & $16(22.5)$ & 0.377 \\
\hline tilar yngaryia & $26(18.2)$ & 12(16.7) & 14(19.7) & 0.636 \\
\hline & $22(15.4)$ & $5(6.9)$ & 17(23.9) & 0.005 \\
\hline 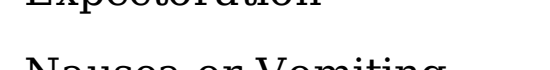 & $14(9.8)$ & $7(9.7)$ & $7(9.9)$ & 0.978 \\
\hline 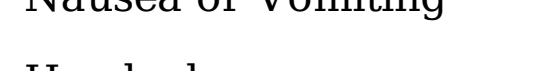 & $7(4.9)$ & $3(4.2)$ & $4(5.6)$ & 0.985 \\
\hline $\begin{array}{l}\text { Onset of symptom to } \\
\text { Hospital admission, }\end{array}$ & $5(3-7)$ & $4(3-5)$ & $6(5-7)$ & 0.000 \\
\hline median (IQR), d & & & & \\
\hline
\end{tabular}




\begin{abstract}
Abbreviations: IQR, interquartile range; COVID-19, Corona virus disease 2019. ${ }^{\text {a }} \mathrm{P}$ values indicate differences between Mild/Moderate and Severe/Critical. $\mathrm{P}<0.05$ was considered statistically significant.
\end{abstract}

Table 2. Laboratory findings of patients with COVID-19 on admission to hospital 


\begin{tabular}{|c|c|c|c|c|c|}
\hline & \multirow{3}{*}{$\begin{array}{l}\text { Normal } \\
\text { Range }\end{array}$} & \multicolumn{3}{|l|}{ Median (IQR) } & \multirow{3}{*}{$\begin{array}{l}\mathrm{P} \\
\text { Value }^{\mathrm{a}}\end{array}$} \\
\hline & & Total & Mild/Moderate & Severe/Critical & \\
\hline & & $(N=143)$ & $(n=72)$ & $(n=71)$ & \\
\hline White blood & $3.5-9.5$ & $3.8(3.2-5.8)$ & $3.6(3.2-4.4)$ & $4.6(3.2-7.3)$ & 0.006 \\
\hline $\begin{array}{l}\text { cell count, } \\
\times 10^{9} / \mathrm{L} \\
\text { Neutrophil }\end{array}$ & $1.8-6.3$ & $3.7(2.2-5.6)$ & $3.2(2.2-4.5)$ & $4.5(2.4-6.6)$ & 0.005 \\
\hline $\begin{array}{l}\text { count, } \times 10^{9} / \mathrm{L} \\
\text { Lymphocyte }\end{array}$ & $1.1-3.2$ & $0.9(0.6-1.2)$ & $1.1(0.7-1.3)$ & $0.7(0.6-1.0)$ & 0.000 \\
\hline $\begin{array}{l}\text { count, } \times 10^{9} / \mathrm{L} \\
\text { Monocyte }\end{array}$ & $0.1-0.6$ & $0.3(0.2-0.4)$ & $0.3(0.2-0.4)$ & $0.3(0.2-0.4)$ & 0.816 \\
\hline $\begin{array}{l}\text { count, } \times 10^{9} / \mathrm{L} \\
\text { Hemoglobin, }\end{array}$ & $115-150$ & $123(119-133)$ & 124(119-136) & $123(116-130)$ & 0.118 \\
\hline Platelet & $125-350$ & $155(128-230)$ & $156(128-228)$ & $154(124-236)$ & 0.990 \\
\hline $\begin{array}{l}\text { count, } \times 10^{9} / \mathrm{L} \\
\text { HDL-C, } \mathrm{mmol} / \mathrm{L}\end{array}$ & $1.29-1.55$ & $0.9(0.8-1.2)$ & $1.1(0.9-1.3)$ & $0.9(0.7-1.0)$ & 0.000 \\
\hline LDL-C, mmol/L & $\square 3.12$ & $2.6(2.2-3.0)$ & $2.6(2.1-3.0)$ & $2.7(2.2-3.0)$ & 0.615 \\
\hline $\begin{array}{l}\text { Plasma glucose } \\
\mathrm{mmol} / \mathrm{L}\end{array}$ & $3.89-5.83$ & $6.7(5.7-8.2)$ & $5.8(5.2-7.5)$ & $7.4(6.1-9.1)$ & 0.000 \\
\hline $\begin{array}{l}\text { Serum sodium } \\
\mathrm{mmol} / \mathrm{L}\end{array}$ & $135-145$ & $137.2(135-140)$ & $138(136-140)$ & $137(134-140)$ & 0.119 \\
\hline $\begin{array}{l}\text { Serum } \\
\text { potassium }\end{array}$ & 3.5-5.5 & $3.4(3.2-3.6)$ & $3.5(3.3-3.6)$ & $3.3(3.1-3.6)$ & 0.005 \\
\hline & $44-120$ & $65(52-76)$ & $61(51-72)$ & $67(52-79)$ & 0.175 \\
\hline $\begin{array}{l}\text { Creatinine, } \\
\mu \mathrm{mol} / \mathrm{L}\end{array}$ & $2.5-6.7$ & $3.6(2.7-5.2)$ & $3.5(2.7-4.8)$ & $4.02(2.7-5.2)$ & 0.225 \\
\hline BUN, mmol/L & 3.4-20.5 & $14.4(10.3-20.0)$ & $13.5(8.0-16.4)$ & 16.2(13.4- & 0.000 \\
\hline TBIL, mmol/L & $34-54$ & $36.0(31.7-39.4)$ & $\begin{array}{l}39.0(36.9- \\
40.0)\end{array}$ & $32.0(30.2-$ & 0.000 \\
\hline Albumin, $g / L$ & $8-40$ & $51.0(34.1-72.6)$ & $42.6(30.3-$ & $34.0)$ & 0.000 \\
\hline AST, U/L & $5-35$ & $40.0(22.0-62.4)$ & $56.8)$ & 61.0(43.5- & 0.002 \\
\hline $\mathrm{ALT}, \mathrm{U} / \mathrm{L}$ & $109-245$ & $256(178-354)$ & $\begin{array}{l}35.8(18.3- \\
46.7)\end{array}$ & $50.0(28.8-$ & 0.000 \\
\hline $\mathrm{LDH}, \mathrm{U} / \mathrm{L}$ & $0-25$ & $12.3(9.8-19.1)$ & $214(153-257)$ & & 0.134 \\
\hline CK-MB, U/L & $0-1$ & $0.5(0.4-1.5)$ & $11.5(9.8-16.7)$ & $321(256-471)$ & 0.000 \\
\hline D-dimer, ug/mL & $20-40$ & $27.4(24-31.5)$ & $0.4(0.3-0.7)$ & $12.8(9.9-20.6)$ & 0.477 \\
\hline
\end{tabular}




$\begin{array}{llllll}\text { APTT, s } & 9-14 & 11.2(10.8-12.4) & 26.2(23.8- & 1.2(0.5-2.9) & 0.347 \\ \text { PT, s } & 0-20 & 37.4(18.1-62.4) & 11.5) & 27.6(24.2- & 0.001 \\ \text { ESR, mm/h } & 0.1-10 & 185.0(26.1- & 12.3) & 30.7) & 0.000 \\ \text { SAA, mg/L } & 0-5 & 638.9) & 25.4(16.7- & 11.4(10.8- & 0.000 \\ \text { CRP, mg/L } & 00.04 & 15.3(5.0-69.1) & 48.6) & 44.7(21.4- & 0.000 \\ \text { PCT, ng/mL } & & 40.6(13.6- & 81.0) & \\ \square 0.04, \mathrm{n}(\%) & & 141.0) & 477.7(209- & \\ 0.04-0.25, \mathrm{n}(\%) & & 39(59.4) & 8.6(4.7-28.6) & 996) & \\ 0.25-0.5, \mathrm{n}(\%) & & 14(9.8) & & 54.8(11.5- & \\ \geq 0.5, \mathrm{n}(\%) & 5(3.5) & 55(76.4) & 100.5) & \\ & & 12(16.7) & 30(42.3) & \\ & & 4(5.6) & 27(38.0) \\ \end{array}$

Abbreviations: HDL-C, high-density lipoprotein cholesterol; LDL-C, low-density lipoprotein cholesterol; BUN, blood urea nitrogen; TBIL, total bilirubin; AST, aspartate aminotransferase; ALT, alanine aminotransferase; LDH, lactate dehydrogenase; CK-MB, creatine kinase-muscle and brain type; APTT, activated partial thromboplastin time; PT, prothrombin time; ESR, erythrocyte sedimentation rate; SAA, serum amyloid A; CRP, Creactive protein; PCT, procalcitonin; IQR, interquartile range; COVID-19, Corona virus disease 2019. ${ }^{\text {a }} \mathrm{P}$ values indicate differences between Mild/Moderate and Severe/Critical. P $<0.05$ was considered statistically significant.

Table 3. Correlation coefficient and $P$ value between items and disease severity 


\begin{tabular}{lll}
\hline & $\mathrm{r}$ & $\mathrm{P}$ \\
\hline Age & 0.458 & 0.000 \\
White blood cell count & 0.229 & 0.006 \\
Neutrophil count & 0.238 & 0.004 \\
Lymphocyte count & -0.295 & 0.000 \\
HDL-C & -0.362 & 0.000 \\
Plasma glucose & 0.383 & 0.000 \\
Serum potassium & -0.237 & 0.004 \\
TBIL & 0.340 & 0.000 \\
Albumin & -0.603 & 0.000 \\
AST & 0.342 & 0.000 \\
ALT & 0.264 & 0.001 \\
LDH & 0.548 & 0.000 \\
D-dimer & 0.477 & 0.000 \\
ESR & 0.284 & 0.001 \\
SAA & 0.58 & 0.000 \\
CRP & 0.477 & 0.000 \\
PCT & 0.345 & 0.000 \\
\hline
\end{tabular}

Abbreviations: HDL-C, high-density lipoprotein cholesterol; TBIL, total bilirubin; AST, aspartate aminotransferase; ALT, alanine aminotransferase; LDH, lactate dehydrogenase; ESR, erythrocyte sedimentation rate; SAA, serum amyloid A; CRP, c-reactive protein; PCT, procalcitonin.

\section{Figures}



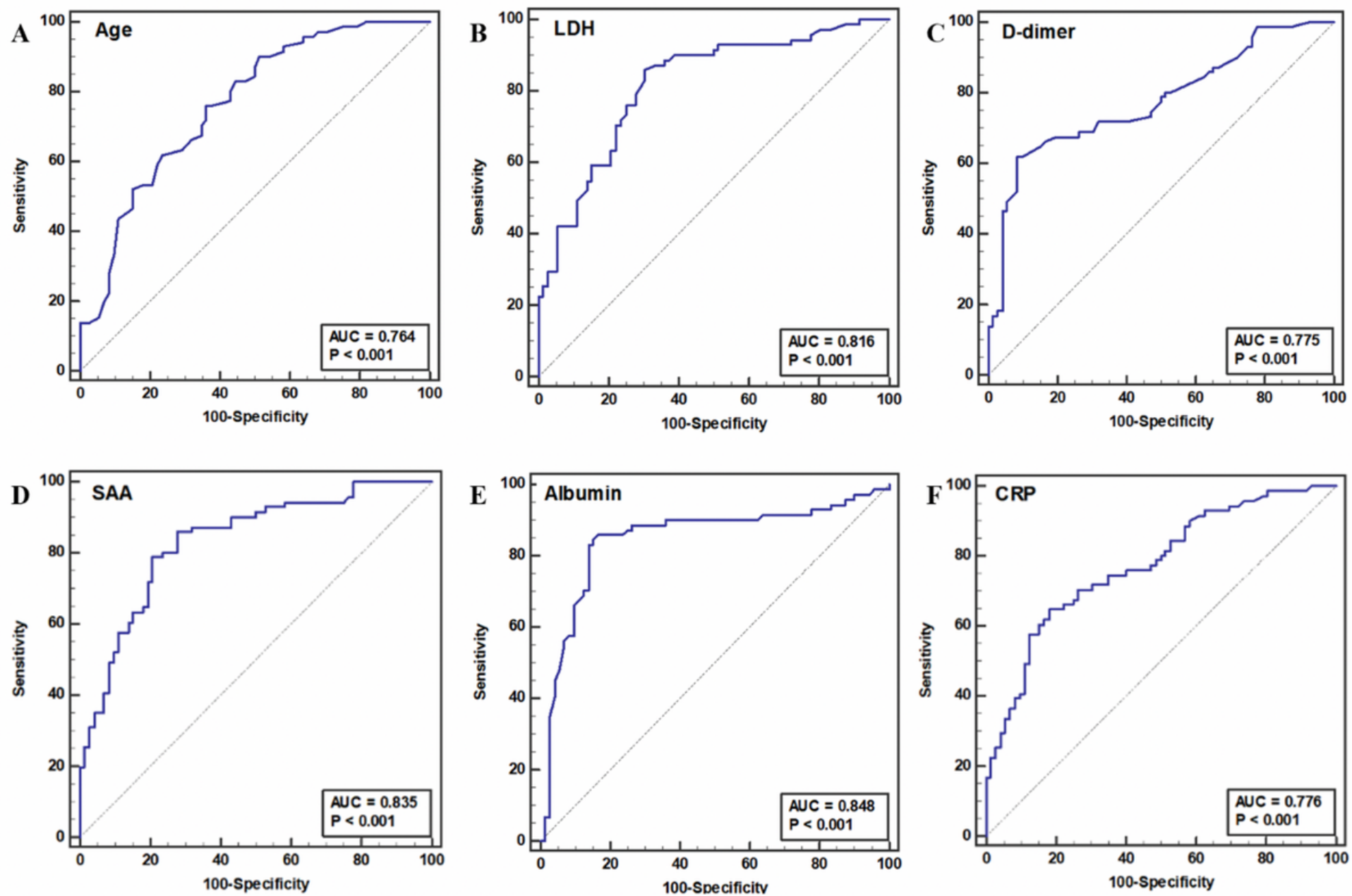

Figure 1

ROC curve of indicators between mild/moderate and severe/critical. (A) age; (B) LDH; (C) D-dimer; (D) SAA; (E)Albumin; (F) CRP 


\section{Comparison}

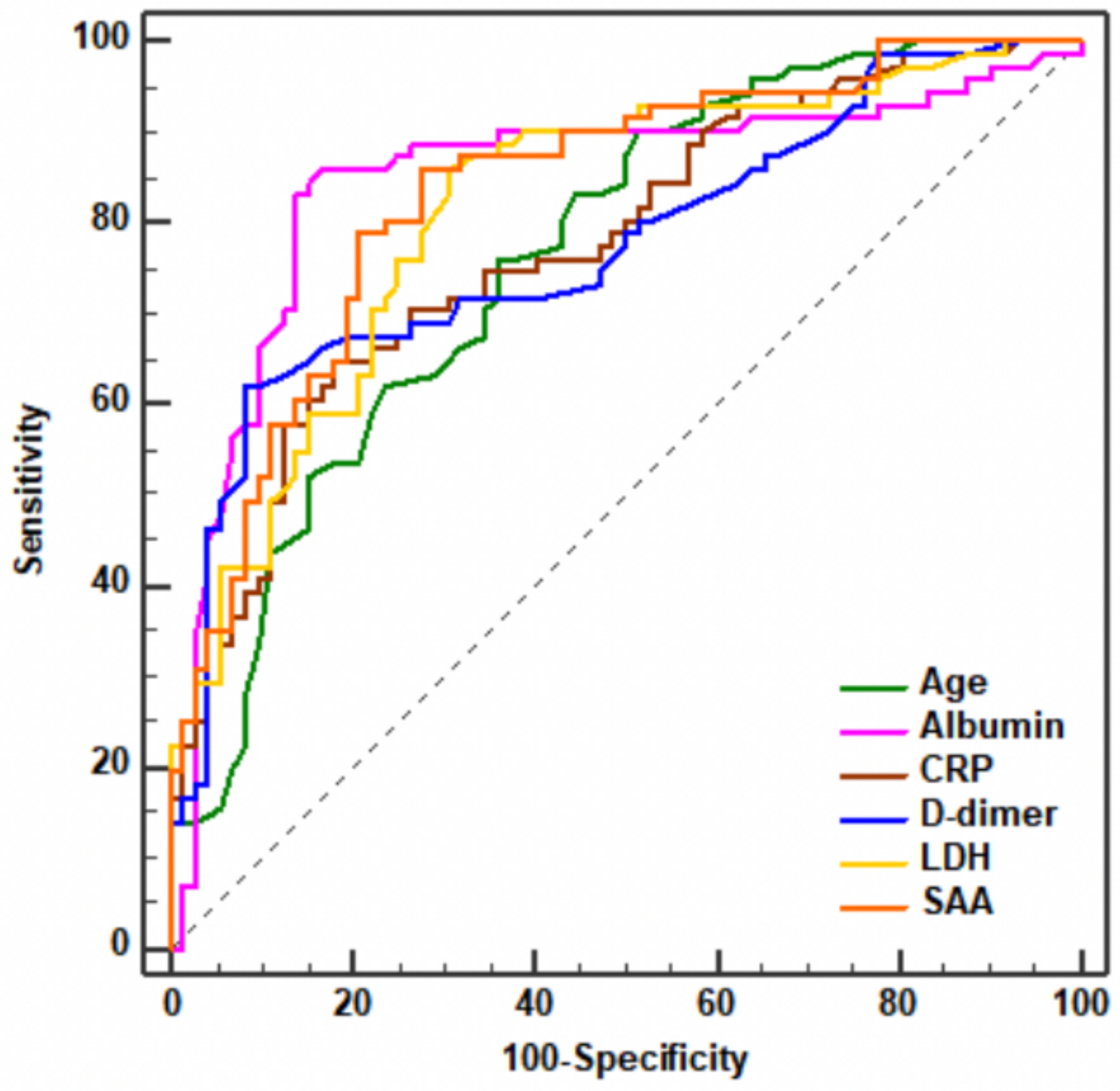

Figure 3

Comparison of the area under the ROC curve of age, LDH, D-dimer, SAA, Albumin, and CRP 

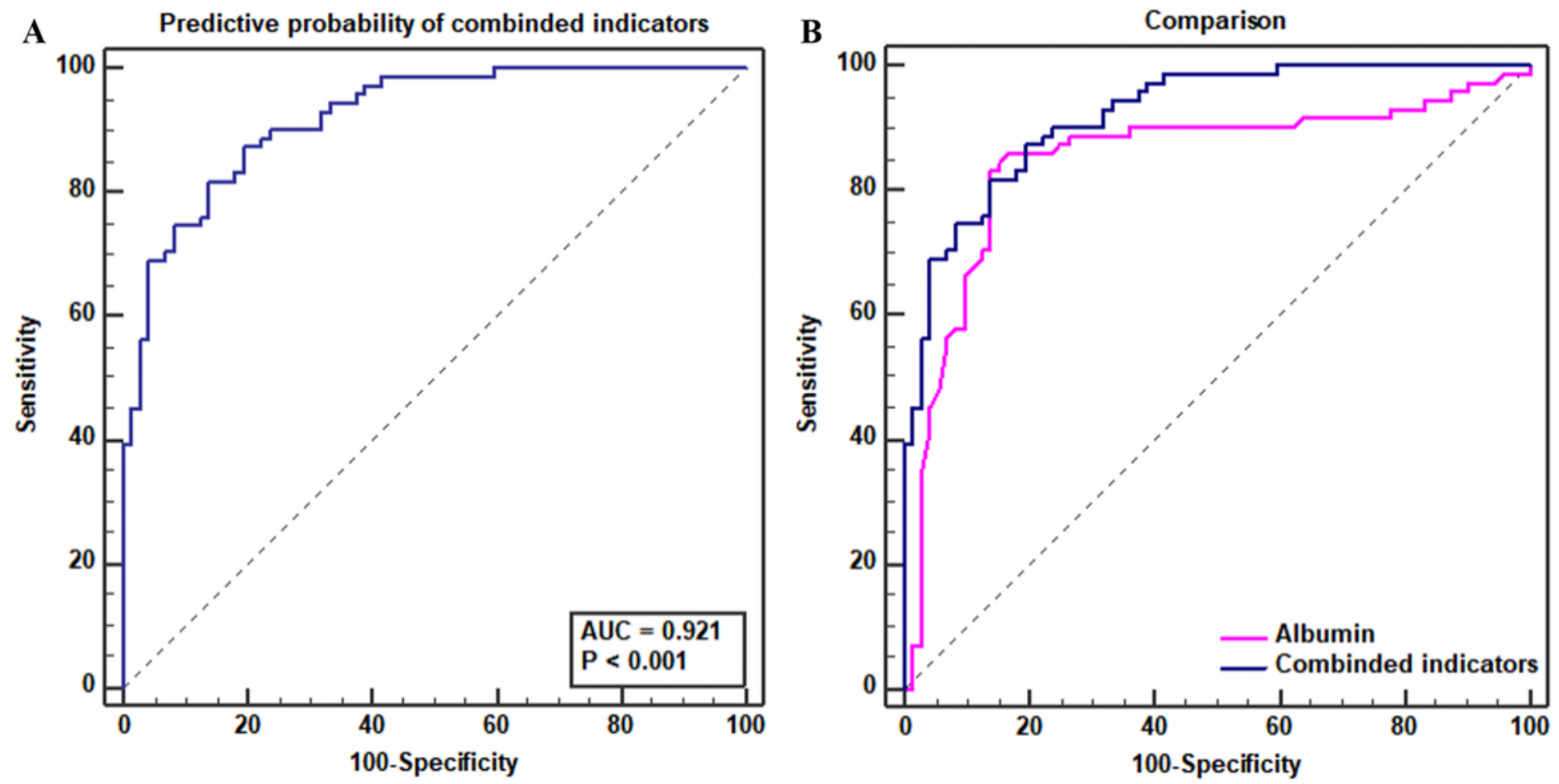

Figure 5

ROC curve of combined indicators for the speculation of disease severity 